\title{
Época de colheita e período de repouso dos frutos de mamão (Carica papaya L.) cv Golden na qualidade fisiológica das sementes
}

\author{
Haverst periods and storage of papaya fruit cv Golden in the seeds physiology quality
}

\section{Edna Maria Mendes Aroucha ${ }^{1}$ Roberto Ferreira da Silva ${ }^{2}$ Jurandi Gonçalves de Oliveira ${ }^{3}$ Alexandre Pio Viana ${ }^{4}$ Messias Pereira Gonzaga ${ }^{5}$}

\section{RESUMO}

Este trabalho teve como objetivo verificar a influência da época de colheita e do período de repouso dos frutos na qualidade fisiológica de sementes de mamão. Os frutos, produzidos no inverno e no verão, da cv Golden, no estádio dois de maturação, foram colhidos e mantidos em câmara a $25^{\circ} \mathrm{C}$ por 12 dias. Após a extração e lavagem das sementes, determinou-se a umidade e matéria seca das mesmas. A secagem foi realizada em estufa com circulação de ar a $30^{\circ} \mathrm{C}$, até atingirem 8 a $10 \%$ de umidade. A germinação e o vigor (primeira contagem de germinação) foram avaliados aos 0, 2, 4, 6, 8, 10 e 12 dias de repouso dos frutos, imediatamente, após a extração das sementes e 30 dias após armazenamento a $15^{\circ} \mathrm{C} . O$ delineamento experimental foi inteiramente casualizado, com quatro repetições. Os tratamentos resultaram da combinação de duas épocas de colheita dos frutos (janeiro e setembro), em oito período de repouso dos frutos $(0,2,4,6,8,10$ e 12 dias) avaliados em dois períodos de armazenamento das sementes (0 e 30 dias). Houve variação na umidade e matéria seca das sementes durante o repouso e a época de colheita dos frutos. $O$ maior vigor das sementes ocorreu em torno de 12 dias de repouso dos frutos, independente do armazenamento das sementes. O período de repouso dos frutos contribuiu para um aumento na germinação das sementes; para frutos colhidos em janeiro, a máxima germinação sementes foi evidenciada em período de repouso inferior ( 9 a 12 dias) aos dos frutos colhidos em setembro (13 dias). Em geral, o armazenamento das sementes proporcionou aumento da germinação das mesmas.
Palavras-chave: armazenamento, germinação, matéria seca, vigor, repouso

\begin{abstract}
This work had as its objective to verify the influence of the harvest season and the period of storage of the fruits for physiologic quality of the papaya seeds. The fruits, developed during the winter and summer time, of $c v$ Golden, at the stage two of maturation were harvested and kept at $25 \mathrm{C}$ for 12 days. After extraction and washing of the seeds, the humidity and dry matter levels were determined. The drying was accomplished using an oven-dried with air circulation at $30^{\circ} \mathrm{C}$ until they reached 8 to $10 \%$ humidity. The seeds germination and vigour (first count of germination test) test were analyzed immediately after extraction of the seeds after fruit rest periods $(0,2,4,6,8,10$ and 12 days) and after storage of the seeds for 30 days at $15^{\circ} \mathrm{C}$. The experimental design used was a completely randomized arrangement in $2 \times 7 \times 2$ factorial scheme with four replications. The treatments of the factorial consisted of the combination of two fruit harvest times (September and January), eight rest periods of the fruits $(0$, $2,4,6,8,10$ and 12 days) and two periods of evaluation of seed storage ( 0 and 30 days). There were variations in the humidity and dry matter of the seeds during the rest and harvesting of the fruits. The best vigour of the seeds occurred around 12 days of fruit rest, independent of seed storage. The rest period of the fruit contributed to increase the seeds germination, to the harvested fruits in January the maximum germination of the seeds was evident at the rest period inferior (9 to 12 days) to the fruits harvested in September (13 days).
\end{abstract}

${ }^{1}$ Engenheiro Agrônomo, Doutor, BR 110, Km 47, 59625-900, Mossoró, RN, Brasil. E-mail: maranhota6@hotmail.com. Autor para correspondência

${ }^{2}$ Engenheiro Agrônomo, Professor Titular, PhD, Departamento de Fitotecnia, Universidade Estadual do Norte Fluminense (UENF), RJ, Brasil.

${ }^{3}$ Engenheiro Agrônomo, Professor Associado, Doutor, Departamento de Fisiologia Vegetal, UENF, Brasil.

${ }^{4}$ Engenheiro Agrônomo, Professor, Associado, Doutor, Departamento de Melhoramento Vegetal, UENF, Brasil.

${ }^{5}$ Engenheiro Agrônomo, Professor, Associado, PhD, Departamento de Melhoramento Vegetal, UENF, Brasil. 
In general terms, the seeds storage increased the seeds germination.

Key words: storage, germination, dry matter, vigour, rest period.

\section{INTRODUÇÃO}

Existem espécies cuja qualidade máxima das sementes está relacionada ao período de repouso dos frutos ou com a maturação dos mesmos, tais como: tomate (DEMIR \& SAMIT, 2001), pimentão (MANTOVANI et al., 1980) e espécies de Curcubitáceas (ARAÚJO et al., 1982; BARBEDO, 1990).

As sementes maduras apresentam desenvolvimento físico e fisiológico que lhes garantem máximo de expressão de vigor (CARVALHO \& NAKAGAWA, 2000), entretanto, há controvérsias quanto à ocorrência de máxima qualidade durante o desenvolvimento e maturação de sementes. Em soja (TEKRONY \& EGLI, 1997) e repolho (REN \& BEWLEY, 1998) as sementes tiveram máxima qualidade no final do período de enchimento das sementes, período classificado como ponto de maturidade fisiológica (máximo vigor). Por outro lado, algumas espécies obtêm maior qualidade das sementes após o período de máxima matéria seca, como por exemplo, arroz (ELLIS \& PIETRA FILHO, 1992) e feijão (SANHEWE et al., 1996).

Em sementes de mamão, a presença de sarcotesta, material gelatinoso que protege a semente (MARIN et al., 1995), pode resultar em germinação lenta e desuniforme (SCHMILDT et al., 1993). De acordo com VASQUEZ(1969), o ideal é que seja extraído a sarcotesta, e a secagem das sementes deve ser realizada em temperatura ambiente, para que se tenha elevada germinação. No entanto, MANICA (1982) e GHERARDI \& VALIO (1976) explicaram que as substâncias inibidoras de crescimento podem estar presentes tanto na sarcotesta quanto na esclerotesta. Segundo os autores, embora tais substâncias inibidoras não sejam totalmente identificadas pelos pesquisadores, atribuise a essas a regulação da germinação.

Existem muitas controvérsias quanto à germinação das sementes de mamão. Para SINGH \& SINGH (1981) e SANTOS et al. (1999), as sementes de mamão recém-colhidas apresentam germinação máxima, mas essa qualidade decresce muito rapidamente após o armazenamento. Já YAHIRO \& ORYOJI (1980) e VIGGIANO et al. (2000) relataram que as sementes recém-colhidas de mamão apresentam baixa germinação devido, provavelmente, a uma dormência pós-colheita. Isto foi confirmado por AROUCHA (2004) em sementes de mamão da cv Golden e híbrido 'Taining 01' que independente do estádio de maturação dos frutos (1, 2, 3, 4 e 5) há baixa germinação inicial, sendo necessário um período de armazenamento das sementes (8 a 16 meses, respectivamente) para que as mesmas obtenham mais de $80 \%$ de germinação.

Este trabalho teve por objetivo verificar o efeito da época de desenvolvimento do fruto e período de repouso pós-colheita sobre a qualidade fisiológica das sementes de mamão da cv Golden, imediatamente, após a secagem e aos 30 dias de armazenamento.

\section{MATERIAL E MÉTODOS}

Os frutos de mamão da cv Golden no estádio 2 de maturação (1/4 maduro, casca com 15 e $25 \%$ de cor amarela) foram colhidos em setembro e janeiro correspondendo ao desenvolvimento dos frutos no inverno e verão, respectivamente, no município de Linhares - ES. O clima da região apresenta temperaturas mínimas, no inverno, entre 15 e $18^{\circ} \mathrm{C}$ e temperaturas máximas, no verão, entre 30 a $32^{\circ} \mathrm{C}$ (FEITOSA, 1986). Os frutos foram transportados, imediatamente, após a colheita em caminhões refrigerados para o município de Campos dos Goytacazes-RJ.

No Laboratório de Tecnologia de Sementes da Universidade Estadual do Norte Fluminense Darcy Ribeiro, os frutos colhidos em setembro e janeiro foram acondicionados e permaneceram em repouso em câmaras frias a $25^{\circ} \mathrm{C}$. As sementes foram extraídas dos frutos em intervalo de dois dias, durante doze dias, visando estudar o efeito de repouso dos frutos sobre a qualidade das sementes. Após sua extração, utilizaram-se peneiras com auxílio de areia para a retirada da sarcotesta e efetuou-se a secagem em estufa com circulação de ar a $30^{\circ} \mathrm{C}$, até atingirem 8 a $10 \%$ de teor de água. Parte das sementes foi submetida, imediatamente, a testes fisiológicos e a outra parte foi acondicionada em embalagem impermeável e armazenada por 30 dias a $15^{\circ} \mathrm{C}$.

Determinou-se o teor de água das sementes em estufa a $105 \pm 3^{\circ} \mathrm{C}$ por 24 horas (BRASIL, 1992), utilizando-se sementes livres da sarcotesta, sem lavagem prévia das sementes, para cada período de repouso dos frutos. Utilizaram-se quatro amostras de $5 \mathrm{~g}$ de sementes, e os resultados foram expressos em porcentagem média de umidade (base úmida). Empregando-se estas mesmas amostras, foi determinado o peso de matéria seca das sementes (100 sementes). A germinação foi realizada em câmara tipo B.O.D com temperatura alternada de $20-30^{\circ} \mathrm{C}$ sob 16 horas no escuro e oito horas de exposição à luz,

Ciência Rural, v.35, n.3, mai-jun, 2005. 
conforme prescrições da Regra para Análise de Sementes (BRASIL, 1992). O vigor foi realizado utilizando-se a porcentagem de plântulas normais na primeira contagem de germinação, aos quinze dias após a instalação do teste de germinação (BRASIL, 1992).

$\mathrm{O}$ experimento foi conduzido em delineamento inteiramente casualizado em arranjo fatorial $2 \times 7 \times 2$, sendo duas épocas de colheita dos frutos (frutos desenvolvidos no verão e no inverno), sete períodos de repouso dos frutos $(0,2,4,6,8,10$ e 12 dias) e dois períodos de armazenamento das sementes (0 e 30 dias), com quatro repetições de $20 \mathrm{~g}$ de sementes. Os dados foram submetidos à análise de variância pelo programa SAS (1989). Para os parâmetros que apresentaram na análise de variância, valores de F significativos em nível de $5 \%$ de probabilidade de erro, foi aplicada a análise de regressão e os modelos foram escolhidos com base na significância dos coeficientes.

\section{RESULTADOS E DISCUSSÃO}

Observa-se, na figura 1 , que o período de repouso dos frutos e a interação deste fator com a época de desenvolvimento do fruto, propiciou efeito sobre a porcentagem de umidade das sementes. Inicialmente, as sementes provenientes de frutos colhidos em setembro apresentaram teor de água superior aos das sementes de frutos produzidos em janeiro. Entretanto, a partir do $4^{\circ}$ dia de repouso, as sementes dos frutos colhidos em janeiro apresentaram tendência de aumento no teor de água, enquanto as sementes dos frutos colhidos em setembro apresentaram redução ao longo do período de repouso.

Comportamento semelhante às sementes de mamão, desenvolvidos em janeiro, foi evidenciado nas sementes de pepino, após o armazenamento dos frutos maduros, em que houve redução no teor de água das sementes, de $40,3 \%$ para $33,46 \%$, de zero aos 15 dias de armazenamento dos frutos (BARBEDO et al., 1997).

As sementes, antes de atingirem a completa maturidade, passam por diversas mudanças morfológicas, fisiológicas e funcionais, com modificações no teor de água das sementes (POPININGS, 1977). Dessa forma, verifica-se que as sementes, independente da época de colheita, no final do repouso dos frutos, apresentaram redução no teor de água, indicando que tanto as sementes quanto os frutos sofrem alterações com o processo de amadurecimento.

Frutos carnosos apresentam poucas diferenças, quanto ao padrão de desidratação das sementes durante a maturação em relação às sementes de frutos secos. Segundo CARVALHO \& NAKAGAWA (2000), as sementes ortodoxas atingem maturidade fisiológica com teor de água de 30 a 50\%, enquanto nas sementes recalcitrantes, a maturidade ocorre em teores de água mais elevados, de 50 a $70 \%$, semelhantes aos teores de água observados em sementes de mamão, apesar dessas não serem classificadas como sementes recalcitrantes (BECWAR et al.,1983).

Observa-se, na figura 2, que o período de repouso dos frutos modificou significativamente o peso de matéria seca das sementes. Inicialmente as sementes provenientes de frutos colhidos em janeiro obtiveram maior peso de matéria seca, se estendendo até o período de 4 dias de repouso dos frutos, entretanto, a partir desse período, constatou-se um declínio acentuado da matéria seca das sementes, contrários às sementes dos frutos colhidos em setembro que tiveram acréscimos a partir desse período.

Resultados semelhantes aos constatados em sementes de frutos colhidos em setembro foram evidenciados por GOMES (1995), em sementes de pepino, onde se observou aumento no peso de matéria seca das sementes após período de repouso dos frutos maduros por 12 dias. Entretanto, diferiu dos resultados relatados por ARAÚJO et al. (1982), que após armazenar frutos de abóbora, em diferentes estádios de maturação, durante 2, 5 e 7 semanas, verificaram aumento no peso de matéria seca das sementes oriundas, apenas, de frutos mais novos armazenados. Tal afirmação foi confirmada, também, em sementes de pepino cv. Pérola por BARBEDO et al. (1997).

O máximo de matéria seca pode indicar o ponto em que as sementes atingem a maturidade fisiológica (CARVALHO \& NAKAGAWA, 2000). No entanto, não deve ser utilizada como a única indicadora, pois alterações fisiológicas e bioquímicas podem ocorrer em sementes, mesmo após máximo acúmulo de matéria seca (ELLIS \& PIETRA FILHO, 1992; SANHEWE et al., 1996).

Observa-se, na figura 3 , que houve efeito significativo da época de colheita dos frutos, período de repouso dos frutos e do armazenamento das sementes sobre a germinação das sementes. A porcentagem de germinação das sementes de frutos recém-colhidos foi baixa, entretanto, as sementes de frutos colhidos em janeiro apresentaram germinação (40\%) superior às sementes colhidas em setembro $(14,75 \%)$

As sementes dos frutos colhidos em janeiro submetidos ao repouso apresentaram acréscimo médio 


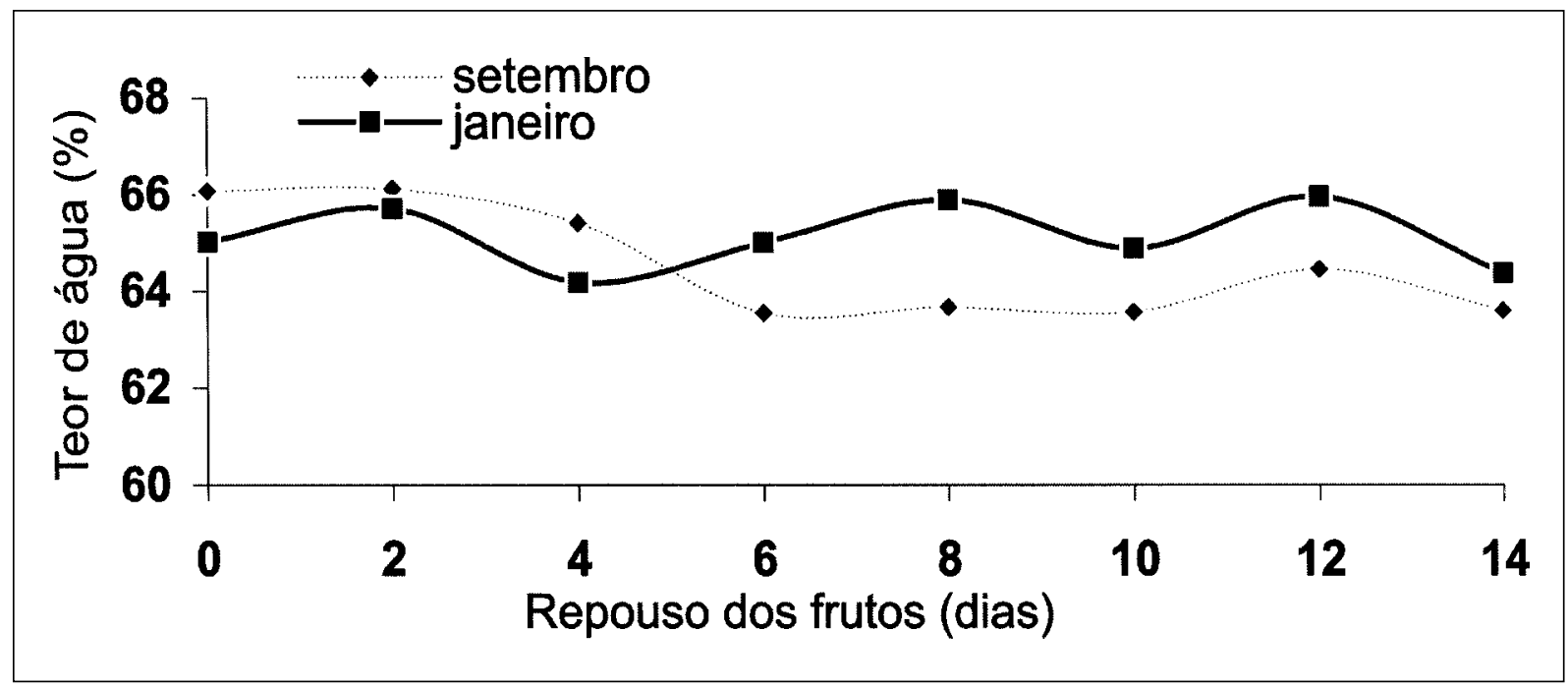

Figura 1 - Evolução do teor de água das sementes de mamão em função do período de repouso dos frutos colhidos em janeiro e setembro de 2003.

de $13,1 \%$ na germinação, quando comparadas às sementes provenientes de frutos colhidos em setembro e mantidos em repouso. O período de repouso dos frutos de mamão proporcionou aumento significativo na germinação das sementes, independente da época de colheita dos frutos. Para frutos colhidos em janeiro, a máxima germinação das sementes foi evidenciada, em períodos de repouso inferior quando comparado aos frutos colhidos em setembro.

Observou-se que, de maneira geral, o armazenamento das sementes contribuiu para um acréscimo médio de 10 a $15 \%$ na porcentagem de germinação das mesmas, exceto para as sementes provenientes de frutos colhidos em janeiro. Notouse, ainda, que durante o período de repouso dos frutos, o armazenamento das sementes propiciou máxima germinação em um período menor de repouso dos frutos e uniformizou as épocas de colheita.

Para frutos colhidos em setembro e janeiro, o período de máxima germinação das sementes ocorreu aos 9 e 11 dias de repouso dos frutos, respectivamente.

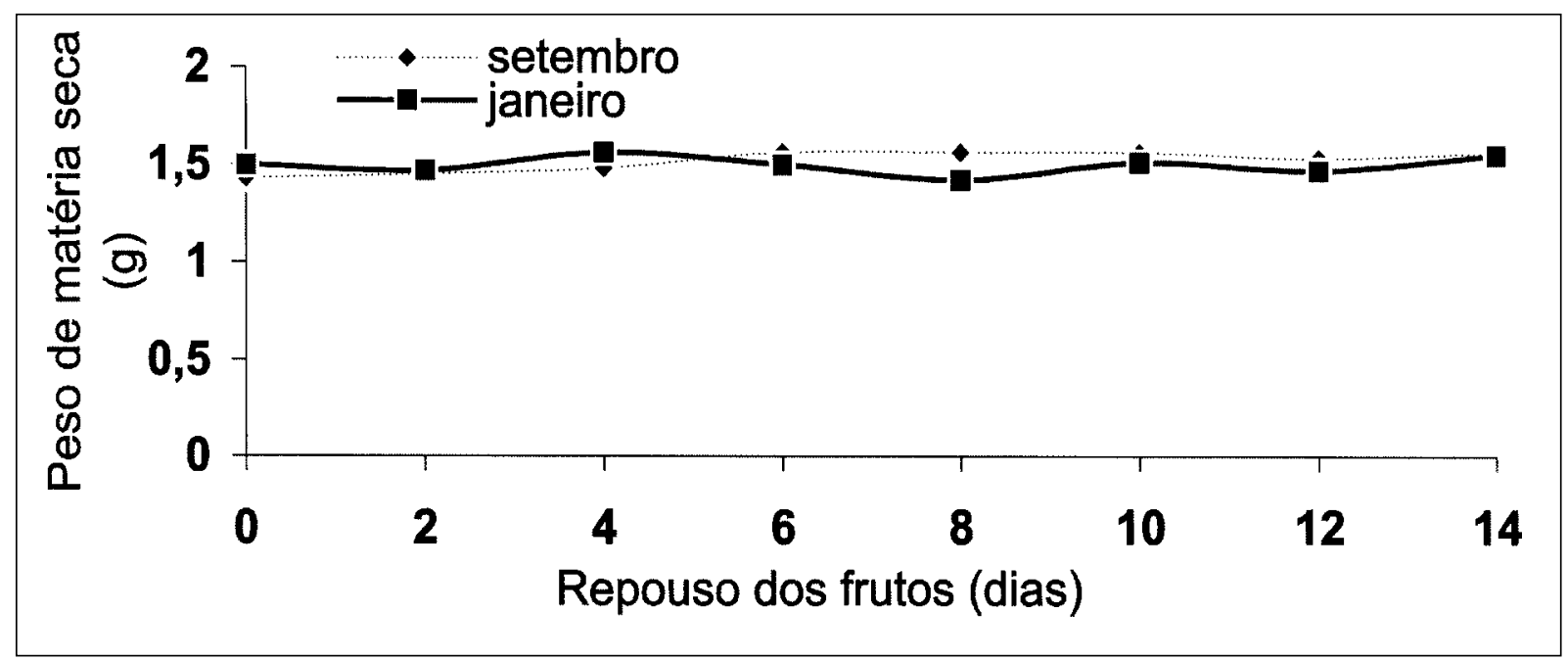

Figura 2 - Evolução do peso de matéria seca das sementes de mamão em função do período de repouso dos frutos colhidos em janeiro e setembro de 2003.

Ciência Rural, v.35, n.3, mai-jun, 2005. 


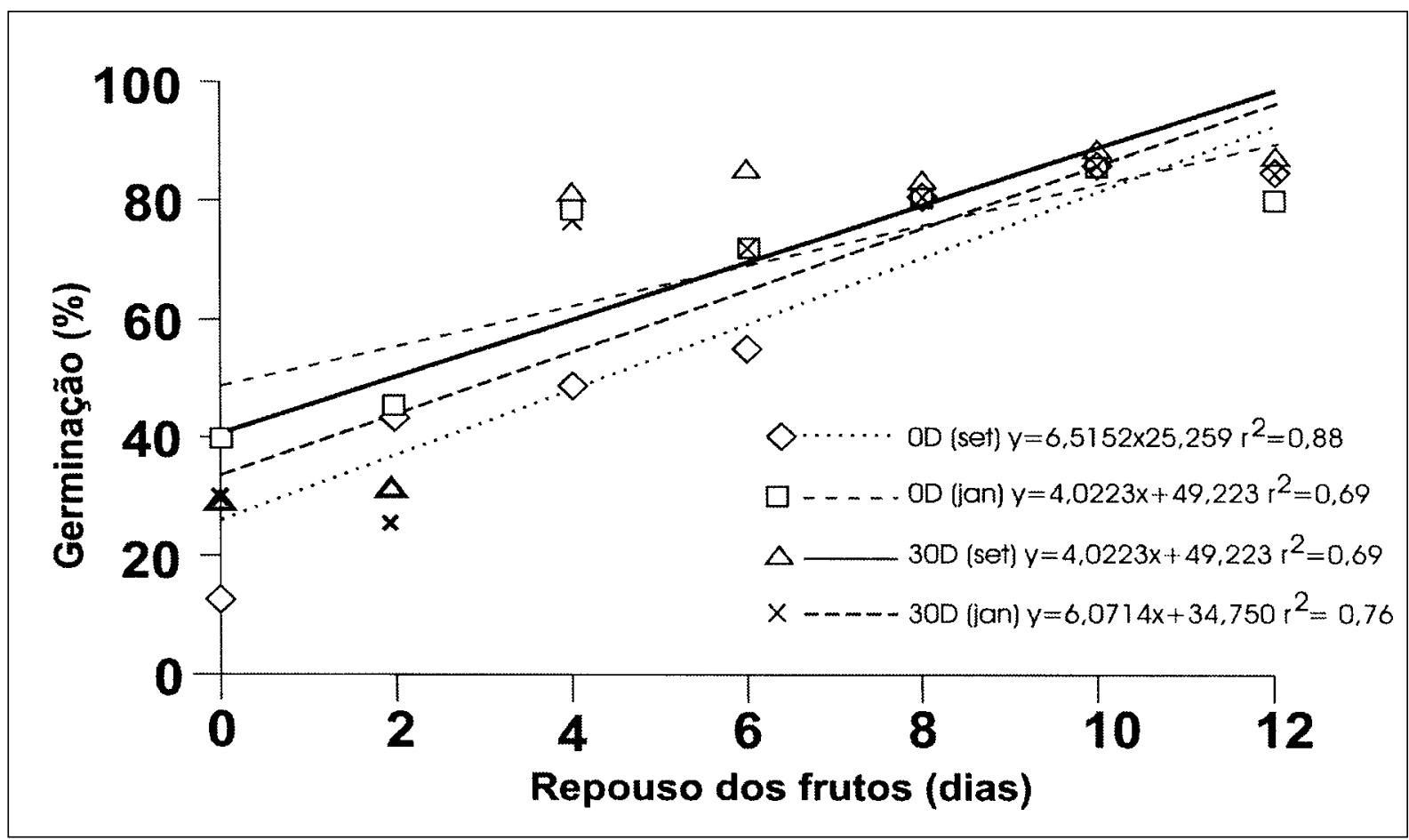

Figura 3 - Porcentagem de germinação das sementes de mamão em função do período de repouso dos frutos colhidos em setembro (set) e janeiro (jan) logo após a secagem das sementes e após 30 dias de armazenamento das sementes.

Verifica-se, na figura 4, um aumento significativo no vigor das sementes, concomitantemente, ao período de repouso dos frutos. Observa-se que, inicialmente, o vigor das sementes era baixo $(7,5 \%)$ e, no final do período de repouso dos frutos, este atingiu valores acima de $80 \%$. Estes resultados foram diferentes dos relatados por BARBEDO et al. (1997), os quais na primeira contagem de germinação, não se mostraram eficientes para avaliar o vigor das sementes de pepino após o repouso dos frutos, entretanto, detectaram-se aumento de vigor das sementes de pepino com o armazenamento dos frutos, verificado por meio de outros testes de avaliação de vigor.

Observa-se que o repouso dos frutos proporcionou que as sementes originassem plântulas vigorosas, entretanto, o maior vigor ocorreu em torno de 12 dias de repouso, independente do armazenamento das sementes (figura 4). O armazenamento das sementes por trinta dias melhorou o vigor das mesmas. Os acréscimos no vigor ocorreram à medida que se aumentou o período de repouso dos frutos (figura 4 ).

O baixo vigor das sementes dos frutos, logo após a colheita, ratifica as informações, na literatura, de que as sementes de mamão possuem irregular e lenta germinação pós-colheita (YAHIRO \& ORYOJI, 1980; VIGGIANO et al., 2000). Observouse que o fator controlador do vigor das sementes recém-colhidas de mamão foi superado, proporcionalmente, ao período em que as mesmas permaneceram no interior do fruto. Tais resultados diferem das sementes de frutos maduros de Curcubita moschata Duch relativo ao período de repouso dos frutos por cinco semanas (ARAÚJO et al.,1982).

$O$ vigor das sementes parece estar associado às mudanças fisiológicas dos frutos de mamão durante o repouso. Os resultados da primeira contagem de germinação mostraram-se eficientes para avaliar o vigor das sementes de mamão, diferentemente dos resultados encontrados nas sementes de melancia (PEDROSA et al.,1987), cenoura (GUEDES \& NASCIMENTO,1988) e pepino (BARBEDO et al., 1997).

\section{CONCLUSÕES}

A umidade e peso de matéria seca das sementes sofrem modificações durante o repouso e colheita dos frutos. O vigor das sementes modifica com o período de repouso dos frutos. $\mathrm{O}$ maior vigor 


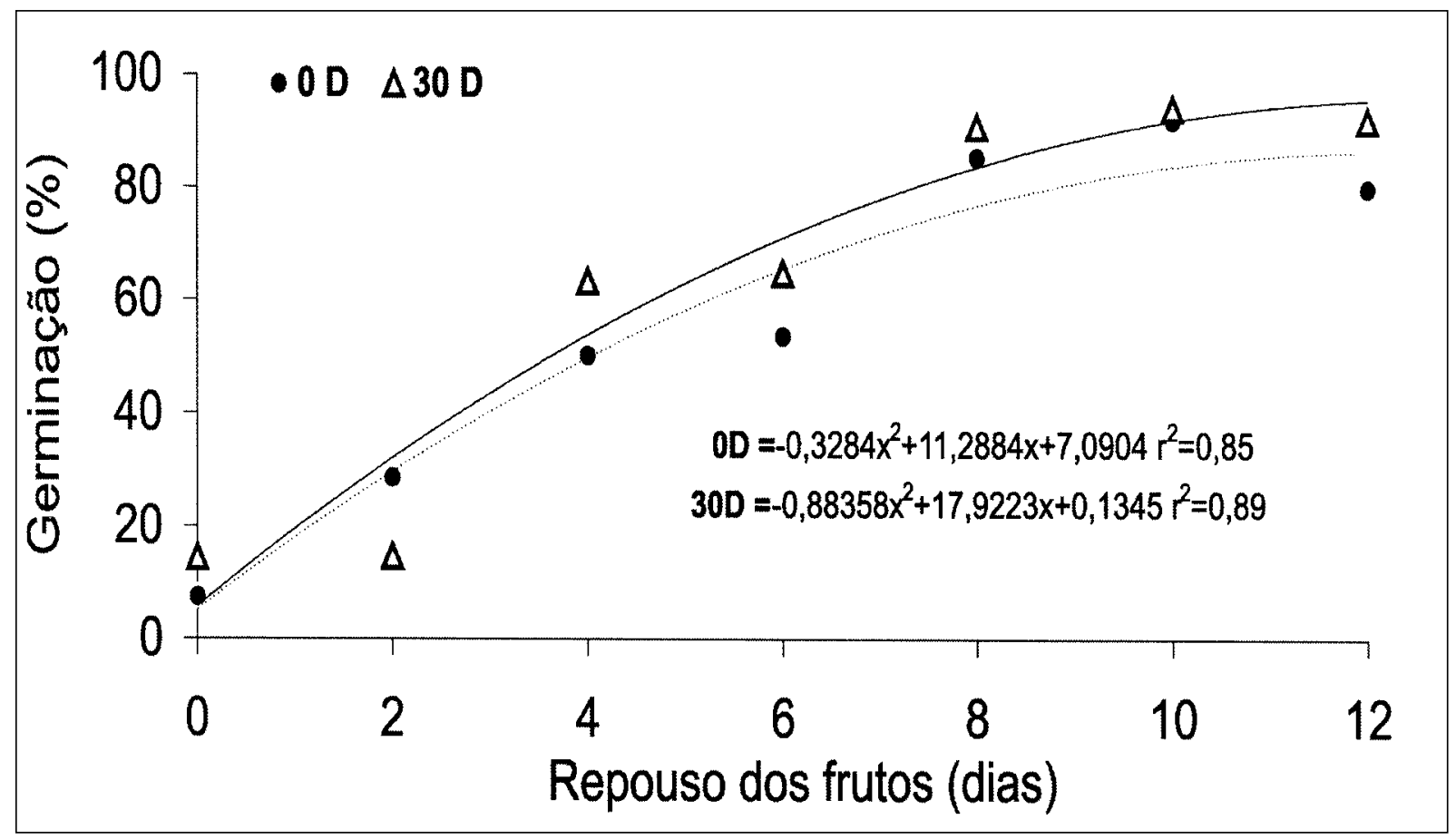

Figura 4 - Primeira contagem de germinação das sementes de mamão em função do período de repouso dos frutos, logo após a secagem e após 30 dias de armazenamento das sementes.

das sementes ocorreu em torno de 12 dias de repouso dos frutos, independente do armazenamento das sementes, enquanto a germinação das sementes, frutos colhidos em janeiro requerem menor período de repouso para obtenção de máxima germinação. De forma geral, o armazenamento das sementes por 30 dias melhorou a germinação das mesmas.

\section{REFÊRENCIAS BIBLIOGRÁFICAS}

ARAÚJO E.F. et al. Influência da idade e armazenamento dos frutos na qualidade de sementes de abóbora. Revista Brasileira de Sementes, Brasília, v.4, n.1, p.77-87, 1982.

AROUCHA, E.M.M. Influência do estádio de maturação, da época de colheita e repouso dos frutos e do osmocondicionamento na qualidade fisiológica de sementes de mamão (Carica papaya L.). 2004. $122 \mathrm{f}$. Tese (Doutorado em Produção Vegetal) - Universidade Estadual do Norte Fluminense Darcy Ribeiro, Campos dos Goytacazes.

BARBEDO, C.J. Influencia da idade e do repouso pós colheita de frutos na qualidade fisiológica de sementes de pepino (Cucumis sativus L.). 1990. 110f. Dissertação (Mestrado em Fitotecnia) - Universidade Estadual de São Paulo.

BARBEDO, C.J. et al. Qualidade fisiológica de sementes de pepino cv pérola em função da idade e do tempo de repouso pós-colheita dos frutos. Pesquisa Agropecuária Brasileira, Brasília, v.32, n.9, p.1-7, 1997.
BECWAR, M.R. et al. Dehydratation effects onfreezing characteristics and survival in liquid nitrogen of desiccationtolerant and desiccation-sensitive seeds. Journal of the American Society for Horticultural Science, v.108, p.613-618, 1983.

BRASIL. Ministério da Agricultura e Reforma Agrária. Regras para análise de sementes. Brasília : SNAA; DNAV; CLAV, 1992. 365p.

CARVALHO, N.M. de; NAKAGAWA, J. Sementes: ciência, tecnologia e produção. 4.ed. Campinas : FUNEP, 2000. $588 \mathrm{p}$.

DEMIR, I.; SAMIT, Y. Seed quality in relation to fruit maturation and seed dry weight during development in tomato. Seed Sci \& Technol, v.29, p.453-462, 2001.

ELLIS R.H.; PIETRA FILHO, C. Seed development and cereal seed longevity. Seed Science Research. v.2, p.9-15, 1992.

FEITOSA, L.R. Carta agroclimática do Espírito Santo. Vitória, ES : Governo do Estado, SEAG-EMCAPA, 1986. (Mapa colorido, Escala: 1:400.000).

GOMES, S.M.S. Influência da idade, coloração externa e armazenamento dos frutos na qualidade de sementes de pepino (Cucumis sativus L.). 1995. 80f. Dissertação (Mestrado em Fitotecnia) - Universidade Federal de Viçosa/MG.

GUEDES, A.C.; NASCIMENTO, W.M. Efeito do tempo de frigorificação das raízes na produção e qualidade de sementes de cenoura, cv. Brasília. Horticultura Brasileira, Botucatu, v.6, n.2, p.7-9, 1988.

Ciência Rural, v.35, n.3, mai-jun, 2005. 
GHERARDI, E.; VALIO, I.F.M. Ocurrence of promoting and inhibitory substances in the seed arils of Carica papaya L. Journal of Horticultural Science, v. 51 , p. $1-4,1976$.

MANICA, I. Fruticultura Tropical 3-mamão. São Paulo : Ceres, 1982, 255p

MANTOVANI, E.C et al. Desenvolvimento e maturação fisiológica de sementes de pimentão (Capsicum annuum L.) Revista Ceres, Viçosa-MG, v.27, n.152, p.356-368, 1980.

MARIN, S.L.D. et al. Recomendações para a cultura do mamoeiro cv. Solo no Estado do Espírito Santo. 4.ed Vitória-ES : EMCAPA, 1995. 57p.

PEDROSA, J.F. et al. Influência da idade e armazenamento na produção e qualidade de sementes de Cucúrbita máxima $x$ moschata. Horticultura Brasileira, Botucatu-SP, v.5, n.2, p.15-17, 1987

POPINIGS, F. Fisiologia da semente. Brasília : AGIPLAN, 1977. 289p.

REN C.; BEWLEY J.D. Seed development, testa structure and precocious germination of Chinese cabbage (Brassica rapa subsp. Pekinensis). Seed Science Research, v.8, p.385397, 1998.

SANHEWE, A.J. et al. Seed development and maturation in Phaseoous vulgaris. II Post-harvest longevity in air dry storage. Journal of Experimental Botany, v.47, p.959 $965,1996$.
SANTOS, R.C.A. et al. Condição ambiental, teor de água e embalagem na viabilidade e no vigor de sementes de mamão. Revista Brasileira de Sementes, Brasília, v.21, n.2, p.194202, 1999

SAS Institute. Statistical user's guide, version 6. 4.ed. Cary, NC : SAS Institute, 1989. V.2, 846p.

SINGH, R.M.; SINGH, I.D. Effect of methods and duration of storage on seed germination and seedling vigour in papaya Seed Research, v.9, p.67-72, 1981

SCHMILDT, E.R. et al. Comparação de métodos físicos de remoção de sarcotesta e de métodos de secagem de sementes de mamoeiro (Carica papaya L.). Revista Brasileira de Sementes, Brasília. v.15, n.2, p.147-151, 1993.

TEKRONY, D.M.; EGLI D.B. Accumulation of seed vigour during development and maturation. In: ELLIS, R.H., et al. (Eds). Basic and applied aspects of seed biology. Boston Kluwer Academic, 1997. p.369-384.

VASQUEZ, R.M. Efecto de diversos tratamientos aplicados a la semilla de Papaya, sobre su poder germinativo. Agricultura Técnica, México, v.2, n.11, p.487-491, 1969.

VIGGIANO, J.R. et al. Ocorrência de dormência em sementes de mamão (Carica papaya L.). Sementes Online, PelotasRS, v.1, n.1, p.6-10, 2000

YAHIRO, M.; ORYOJI Y. Effects of gibberellin and cytokinin treatments on the promotion of germination in papaya, seeds. Mem Fac Agric, Kagoshima Univ, v.16, p.45-51, 1980. 